\title{
Weight Loss Improves Pregnancy and Livebirth Outcomes in Young Women with Early-Stage Endometrial Cancer and Atypical Hyperplasia
}

\author{
Yanfang Zhang ${ }^{1} *$ \\ Dan $\mathrm{Li}^{1}{ }^{1 *}$ \\ Qi Yan' \\ Xueru Song' \\ Wenyan Tian' \\ Yingmei Wang' \\ Fei Teng' \\ Likun Wei ${ }^{1}$ \\ Jinghua Wang ${ }^{2}{ }^{2}$ \\ Huiying Zhang' \\ Fengxia Xue'
}

'Department of Gynecology and Obstetrics, Tianjin Medical University General Hospital, Tianjin, China; Tianjin Key laboratory of Female Reproductive Health and Eugenics, Tianjin, People's Republic of China; ${ }^{2}$ Laboratory of Epidemiology, Tianjin Neurological Institute, Department of Neurology, Tianjin Medical University General Hospital, Tianjin, People's Republic of China

*These authors contributed equally to this work

\begin{abstract}
Purpose: To evaluate the effects of body weight loss on reproductive outcomes in young women with early-stage endometrial cancer (EC) and atypical hyperplasia (AH) who underwent fertility-sparing therapy.

Patients and Methods: Patients with well-differentiated EC ( $\mathrm{n}=8$, FIGO stage Ia) and AH $(\mathrm{n}=36)$ who achieved complete regression after fertility-sparing therapy were retrospectively reviewed. Patients were divided into a weight loss group $(\mathrm{n}=25)$ and a non-weight loss group $(n=19)$. Subgroup analysis according to body mass index and relative weight loss were performed to investigate the effect of weight loss on pregnancy and live birth outcomes. Univariate and multivariate logistic regression analyses were undertaken to determine pregnancy-associated factors.
\end{abstract}

Results: Mean body weight and body mass index at pre-progestin treatment and at fertility treatment initiation were $70.63 \pm 12.03$ and $67.08 \pm 8.18 \mathrm{~kg}$, respectively, $27.06 \pm 4.44$ and 25.73 $\pm 3.15 \mathrm{~kg} / \mathrm{m}^{2}$, respectively. Twenty-five patients $(56.82 \%)$ lost weight, the median absolute weight loss was $5.00 \mathrm{~kg}(1.00-34.50)$, and the median relative weight loss was $6.70 \%(1.00$ $36.00 \%)$ over a median of 12 months (5.00-97.00). A favorable pregnancy rate (65.91\%) and live birth rate $(50.00 \%)$ were achieved. The pregnancy and live birth rates were meaningfully higher in the weight loss group than in the non-weight loss group ( $88.00 \%$ vs $36.84 \%$, $P=0.000 ; 64.00 \%$ vs $31.58 \%, P=0.033$ ); weight loss $\geq 5 \%$ significantly increased pregnancy and live birth rate in patients with BMI $\geq 25 \mathrm{~kg} / \mathrm{m}^{2}$. The risk ratio of weight loss $\geq 5 \%$ in multivariate logistic analysis for pregnancy was $10.448(1.102,99.056, P=0.041)$.

Conclusion: Weight loss could positively affect pregnancy rate and improve live birth rate in overweight and obese women with early-stage EC and AH during/after fertility-sparing therapy. Weight loss $\geq 5 \%$ increased pregnancy and livebirth rates significantly in overweight and obese women.

Keywords: weight loss, reproductive outcomes, fertility-sparing therapy, endometrial cancer, atypical hyperplasia

\section{Introduction}

Endometrial cancer (EC), also known as adenocarcinoma of the endometrium, is the most common malignancy of the female genital tract. In the United States, it is estimated that 63,230 new uterine cancer cases will occur in 2018 , with 11,350 deaths resulting from the disease. ${ }^{1}$ The EC incidence rate was found to increase over time because of increased life expectancy and the obesity epidemic., ${ }^{2,3}$ Although the majority of cases are diagnosed in postmenopausal patients, ${ }^{4} 14 \%$ 
of cases are diagnosed in premenopausal women and 5\% of whom are under 40 years, ${ }^{5} 70 \%$ of affected women are nulliparous. ${ }^{6}$

In younger cancer survivors, reproductive health is an issue of great importance and more attention is needed in the health care setting throughout the cancer experience, beginning at diagnosis. Standard surgical treatment for EC and $\mathrm{AH}$ involves hysterectomy and bilateral salpingo-oophorectomy with or without pelvic lymphadenectomy, which deprives patients of the chance of future pregnancy. The trend toward late childbearing has made fertility preservation a major issue to improve quality of life for these young women. In these young women, the majority of cases are endometrioid, focal, well-differentiated EC, limited to the endometrium which generally shows a good long-term prognosis. Many studies have indicated fertility-sparing management may be considered in selected patients, and it is consistently recognized that progestin is a safe and effective fertility-sparing treatment. ${ }^{7}$ Other conservative approaches, including levonorgestrelreleasing intrauterine devices (LNG-IUD) and the use of gonadotropin-releasing hormones have been researched, these may either be used separately or together. ${ }^{4}$ Another significant concern regarding fertility preservation is pregnancy following conservative treatments. However, as reported recently in a systematic review and meta-analysis, pregnancy and live birth rates were low at $26.8 \%$ and $20.5 \%$, respectively. ${ }^{8}$ More careful implementation of fertility-sparing treatment options for selected reproductive-age women is needed to improve fertility potential. Surgical resection of the diseased endometria followed by continuous progestin or with placement of a LNG-IUD has been reported to be an effective fertility-sparing treatment to improve oncologic and reproductive outcomes, ${ }^{9-11}$ given the limited number of cases, further randomized-controlled studies are necessary to confirm and update these data. Various practice guidelines are predominantly focused on fertility, but optimal management of patients who desire future fertility is unknown and there is still no consensus as to which type of procedure is deemed most optimal.

The etiology and pathogenesis of EC have not yet been fully understood. It is well established that obesity is not only the leading risk factor in the development of EC and $\mathrm{AH}$, but that it also disrupts female fertility. ${ }^{12-14}$ However, little is known about the impact of weight loss on the oncologic and reproductive outcomes in $\mathrm{EC}$ and $\mathrm{AH}$ patients following fertility-preserving treatment. A study in Korea, published in 2017, indicated that weight change during fertility-sparing progestin therapy in young women with early EC has minor influence on oncologic and reproductive outcomes. ${ }^{15}$ Nevertheless, evidence in developing countries is still lacking. In this study, we report our experience on the fertility sparing of $\mathrm{EC}$ or $\mathrm{AH}$ who received non-surgical intervention for weight loss with an aim to verify the importance of weight loss interventions to improve pregnancy and live birth outcomes; we also aimed to provide some procedures in clinical practice and management of those who require fertility-sparing treatment diagnosed with $\mathrm{EC}$ or $\mathrm{AH}$.

\section{Materials and Methods \\ Patient Selection}

This retrospective study included women younger than 40 years, diagnosed with early-stage $\mathrm{EC}$ or $\mathrm{AH}$, and who desired fertility-sparing management from May 2005 to May 2019. Patient selection is detailed in Figure 1.

Inclusion criteria were (1) histologically proven $\mathrm{AH}$ or well-differentiated EC without myometrial invasion on magnetic resonance imaging (MRI), (2) no signs of extrauterine involvement, (3) a strong desire to preserve fertility, (4) age $\leq 40$ years, (5) no contraindication for progestin treatment or pregnancy, and (6) good compliance for treatment.

Exclusion criteria were (1) Lost to follow up, data not extractable, (2) unavailable data for body weight and height prior to progestin treatment and at initiation of fertility treatment, (3) received standard surgical treatment at diagnosis pathologically or failure after conservative treatment, (4) achieved complete regression and did not wish to conceive immediately, and (5) women without a partner when the data were collected.

Approval was obtained from the Ethics Committee of Tianjin Medical University General Hospital Ethics Committee. All patients were provided full information regarding the risks and benefits of conservative treatments, and all of the patients provided signed consent.

\section{Information Collection and Diagnosis Criteria}

Medical records were reviewed for demographic, clinicopathological, and oncologic and reproductive data. Blood sample data collected included cancer antigen $\mathrm{CA}_{125}, 75-\mathrm{g}$ oral glucose tolerance test results (OGTT); OGTT was not performed for patients with diabetes mellitus, fasting blood glucose (FBG) levels, and fasting insulin (FINS) were detected only. 
Total number of patients $\leq 40$ years diagnosed with well differentiated EC (stage 1a) or $\mathrm{AH}(\mathrm{n}=119)$

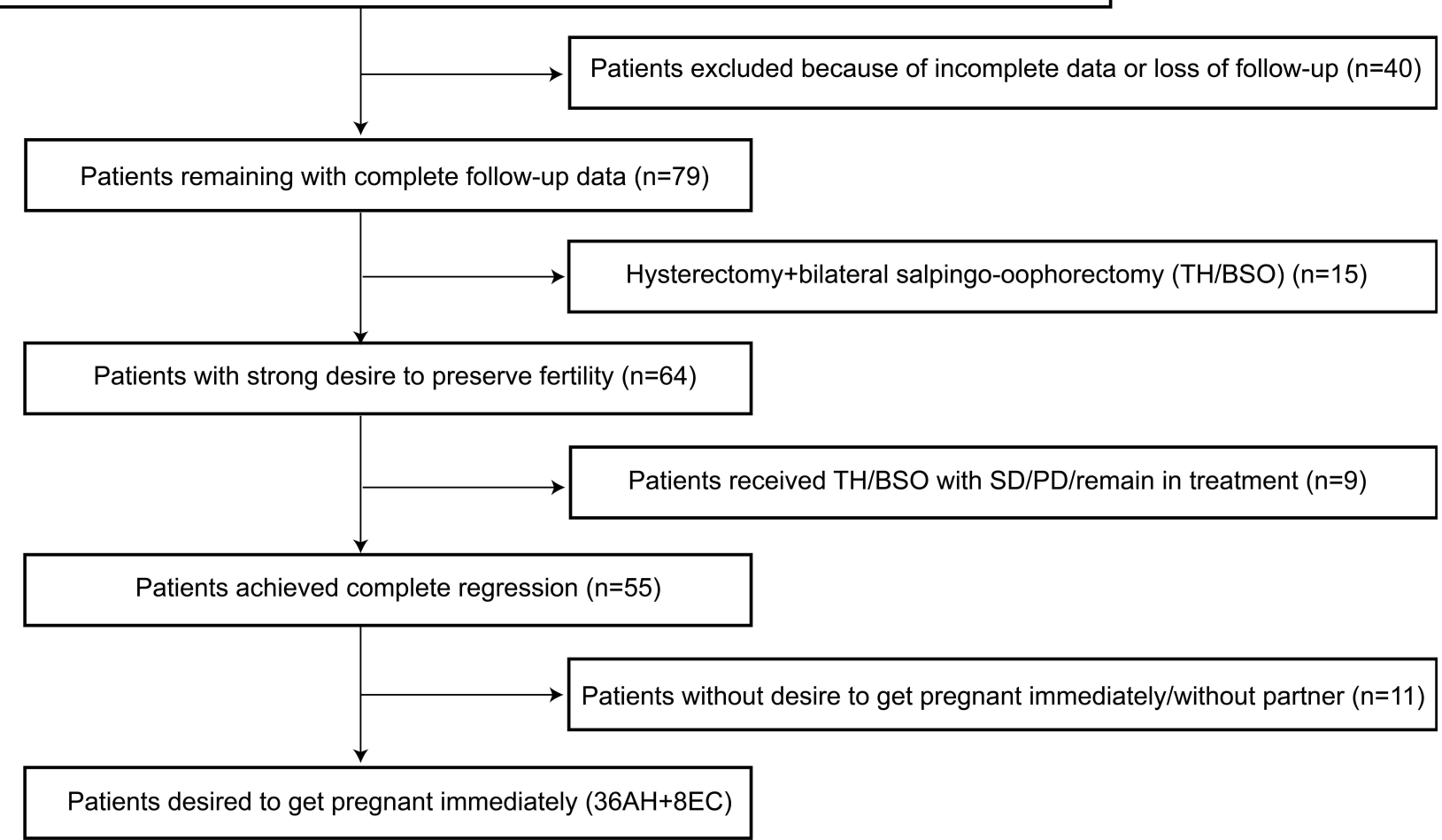

Figure I Flowchart for patients' selection.

Abbreviations: EC, endometrial cancer; TH/BSO, Hysterectomy+bilateral salpingo-oophorectomy; AH, atypical hyperplasia; SD, stable disease; PD, progressive disease.

The homeostasis model assessment of insulin resistance (HOMA-IR) index $(\mathrm{FBG}[\mathrm{mmol} / \mathrm{L}] \times$ FINS $[\mu \mathrm{U} / \mathrm{mL}] / 22.5)>$ 2.69 was defined as insulin resistance (IR). Body weight prior to progestin treatment (body weight $_{1}$ ) and at fertility treatment initiation (body weight ${ }_{2}$ ) were collected to obtain body weight change; body mass index (BMI) was calculated and recorded as $\mathrm{BMI}_{1}$ and $\mathrm{BMI}_{2}$, respectively. Overweight was defined as $\mathrm{BMI} \geq 25 \mathrm{~kg} / \mathrm{m}^{2}$, and obesity as BMI $\geq 30 \mathrm{~kg} / \mathrm{m}^{2}$.

All patients were pathologically diagnosed based on results of endometrial biopsy during dilation and curettage along with hysteroscopy. Pathologic diagnosis was reviewed by two experienced gynecological pathologists according to the World Health Organization pathological classification (2014). If their opinions differed, a seminar was held in the pathological department for the final diagnosis. Polycystic ovarian syndrome (PCOS) was diagnosed according to the Rotterdam 2003 criteria.

\section{Assessment and Intervention}

Following confirmation of $\mathrm{EC}$ or $\mathrm{AH}$, appropriately selected patients who desired fertility preservation were referred to a reproductive endocrinologist to assess reproductive fertility.
In women who were overweight or obese, health education was performed and weight loss was recommended.

\section{Progestin Therapy and Response}

Patients received a daily oral dose of 250-500 mg medroxyprogesterone acetate (MPA) or 160-320 mg megestrol acetate (MA). Metformin $1500 \mathrm{mg}$ /day was administered concurrently for patients with insulin resistance. Metformin therapy was continued after progestin administration until conception. Endometrial biopsy during dilation and curettage along with hysteroscopy was performed 3 months after initiating progestin administration. Progestin was continued to the second negative biopsy.

The response to progestin was categorized as a complete response (CR), a partial response (PR), stable disease (SD), or progressive disease (PD) according to the pathology. CR was defined as the absence of evidence of hyperplasia or carcinoma, PR as residual hyperplasia or carcinoma with a degenerating and atrophic endometrial gland, SD as a persistent lesion, and PD as progression to a lesion of higher grade or clinically progressive disease including myometrial invasion, extrauterine disease, or lymph node metastasis. After 6 
months progestin administration, standard surgical treatment was recommended for patients diagnosed with SD and PD. For patients remained SD but refused hysterectomy or remained PR after 6 months of treatment, the dosage of progestin was increased (maximum dose $500 \mathrm{mg}$ /day for MPA, $320 \mathrm{mg} /$ day for MA) and the treatment was continued up to further two 3-months.

\section{Fertility Treatment}

We recommended that the patients undergo fertility treatment as soon as possible after CR. They underwent hysterosonosalpingography, antral follicular count via transvaginal ultrasound (TVS), hormone evaluation and partner spermiogram.

The fertility treatment is as follows: (1) assisted reproductive technology therapy (ART), which including induced ovulation and intrauterine insemination, and in vitro fertilization (IVF)/intracytoplasmic sperm injection and (2) non-ART (pregnancy spontaneously), which includes natural conception and timed intercourse. Women who refused to seek pregnancy with ART were authorized to seek pregnancy spontaneously if the above tests were normal.

For CR patients without recent pregnancy plan or patients' postpartum, low-dose cyclic progestin, or a LNG-IUD was administered to prevent recurrence. They were followed up every 3-6 months. TVS and endometrial biopsy with hysteroscopy to evaluate the endometrium. Pelvic MRI, serum CA-125 and HE-4 were used for follow-up of EC patients annually.

All patients were followed till December 2020.

\section{Study End-Points and Definitions}

Study end-points were patients' clinical pregnancies and live births. Early pregnancy loss was also recorded. Clinical pregnancy was defined as observation of a gestational sac on a transvaginal ultrasound scan. Biochemical pregnancy was diagnosed as human chorionic gonadotropin $\geq 25 \mathrm{mIU} / \mathrm{mL}$. Early pregnancy loss including loss of an intrauterine pregnancy $<12$ weeks and biochemical pregnancy losses were also included. A live birth was defined as parturition of newborns weighing $\geq 1000$ $\mathrm{g}$ after at least 28 weeks of gestation.

Endometrial thickness was measured via TVS during ovulation or at the embryo transfer date.

\section{Statistical Analysis}

Continuous variables are presented as mean (standard deviation) or median (interquartile range), and categorical variables are presented as number (percentage). The Mann-Whitney $U$-test was used for the univariate analysis of the relationship between weight loss and pregnancy. Frequency distributions were compared using the chisquared test or Fisher's exact test. According to logistic regression analysis sample content and independent variable number requirements, four independent variables were included in the multivariate analysis were included in the multivariate analysis. Differences in outcomes were compared between the two groups using univariate and multivariate logistic regression models and are presented as unadjusted and adjusted (age at diagnosis, treatment time, endometrial thickness on the day of ovulation or transplantation, and weight loss proportion) relative risk, respectively, with 95\% confidence intervals. All statistical analyses were performed using SPSS for Mac (version 23.0; IBM), and two-tailed $P$ values $<0.05$ were considered statistically significant.

\section{Results}

\section{Patient Characteristics}

A total of $8 \mathrm{EC}$ and $36 \mathrm{AH}$ patients who met the inclusion criteria were enrolled in the study, patients' characteristics are summarized in Table 1; The average age, mean BMI, and HOMA-IR at diagnosis was 31.63 years, $27.06 \mathrm{~kg} / \mathrm{m}^{2}$ and 4.70 , respectively. Thirty $(68.18 \%)$ and $32(72.73 \%)$ patients were diagnosed as overweight/obese or as having insulin resistance, respectively. The BMI and HOMA-IR were significantly higher, and the incidence of BMI $\geq 25 \mathrm{~kg} / \mathrm{m}^{2}$ and insulin resistance were also meaningfully higher in the weight loss group.

Thirty-four (77.27\%) patients were nulligravida, and 42 (95.45\%) were nulliparous; $33(75.00 \%)$ patients were infertile; and 23 (52.30\%), 9 (20.45\%) and 6 (13.64\%) patients were diagnosed with PCOS, hypertension, and diabetes mellitus, respectively. Twenty-five (56.82\%) patients were administered medroxyprogesterone acetate (MPA), and 19 (43.18\%) were administered megestrol acetate (MA) as conservative treatment. There were no significant differences between the groups concerning these parameters. 
Table I Patients Basic Characteristics

\begin{tabular}{|c|c|c|c|c|}
\hline Parameters & Total Patients $(n=44)$ & Weight Loss $(n=25)$ & Non-Weight Loss $(n=19)$ & $P$ value \\
\hline Age at diagnosis (years) & $31.63 \pm 3.89$ & $30.72 \pm 3.74$ & $32.84 \pm 3.86$ & 0.073 \\
\hline Hormone FSH (mlU /mL) & $6.01(2.60-15.00)$ & $5.06(2.60-10.97)$ & $6.21(2.62-15.00)$ & 0.407 \\
\hline $\mathrm{LH}(\mathrm{mlU} / \mathrm{mL})$ & $5.77(1.42-15.80)$ & $4.16(1.42-12.80)$ & $5.27(2.30-15.80)$ & 0.286 \\
\hline $\mathrm{E}_{2}(\mathrm{pg} / \mathrm{mL})$ & $36.60(12.55-82.60)$ & $32.08(17.00-66.00)$ & $39.00(12.55-82.60)$ & 0.058 \\
\hline Abnormal menstruation, $n(\%)$ & $40(90.91)$ & $22(55.00)$ & $18(45.00)$ & 0.622 \\
\hline Infertility, n (\%) & $33(75.00)$ & $19(57.60)$ & $14(42.40)$ & 1.000 \\
\hline Nulligravida, $n$ (\%) & $34(77.27)$ & $19(55.90)$ & $15(44.10)$ & 1.000 \\
\hline Nulliparous, $n$ (\%) & $42(95.45)$ & $25(59.50)$ & $17(40.50)$ & 0.181 \\
\hline Histology n (\%): Endometrial cancer & $8(18.18)$ & $3(37.50)$ & $5(62.50)$ & 0.262 \\
\hline Atypical hyperplasia & $36(81.82)$ & $22(61.10)$ & $14(38.90)$ & \\
\hline Body mass index $\left(\mathrm{kg} / \mathrm{m}^{2}\right)$ & $27.06 \pm 4.44$ & $29.02 \pm 4.07$ & $24.48 \pm 3.55$ & 0.000 \\
\hline Body mass index $\geq 25, n$ (\%) & $30(68.18)$ & $22(73.30)$ & $8(26.70)$ & 0.001 \\
\hline HOMA-IR & $4.70 \pm 3.33$ & $5.66 \pm 3.81$ & $3.43 \pm 2.03$ & 0.026 \\
\hline Insulin resistance, $n(\%)$ & $32(72.73)$ & $23(71.90)$ & $9(28.10)$ & 0.001 \\
\hline Metformin, n (\%) & $32(72.73)$ & $23(71.90)$ & $9(28.10)$ & 0.001 \\
\hline PCOS, n (\%) & $23(52.30)$ & $12(52.20)$ & II (47.80) & 0.515 \\
\hline Hypertension, n (\%) & $9(20.45)$ & $6(66.70)$ & $3(33.30)$ & 0.710 \\
\hline Diabetes mellitus, $n(\%)$ & $6(13.64)$ & $4(66.70)$ & $2(33.30)$ & 0.684 \\
\hline Progestin MPA, $n(\%)$ & $25(56.82)$ & $13(52.00)$ & $12(48.00)$ & 0.176 \\
\hline MA, $n(\%)$ & $19(43.18)$ & $6(31.60)$ & $13(68.40)$ & \\
\hline
\end{tabular}

Abbreviations: $\mathrm{FSH}$, Follicle stimulating hormone; LH, Luteinizing hormone; $\mathrm{E}_{2}$, Estradiol; Body mass index , Body mass index at pre-progestin treatment; HOMA-IR, Homeostasis model assessment of insulin resistance index; PCOS, Polycystic ovarian syndrome; MPA, Medroxyprogesterone acetate; MA, Megestrol acetate.

\section{Weight Loss and Group Divisions}

Of the 44 total patients, mean body weight 1 and body weight $_{2}$ were $70.63 \pm 12.03 \mathrm{~kg}$ and $67.08 \pm 8.18 \mathrm{~kg}$, respectively; mean $\mathrm{BMI}_{1}$ and $\mathrm{BMI}_{2}$ were $27.06 \pm 4.44 \mathrm{~kg} / \mathrm{m}^{2}$ and $25.73 \pm 3.15 \mathrm{~kg} / \mathrm{m}^{2}$, respectively. The median time interval between the two body weight measurements was 12 months (range, 5-97 months). Twenty-five patients (56.82\%) demonstrated weight loss (weight loss group), with a median absolute weight loss of $5.00 \mathrm{~kg}(1.00$ $34.50 \mathrm{~kg}$ ) and a relative weight loss (weight loss ratios) of $6.70 \%(1.00-36.00 \%)$.(Table 2)

In patients with BMI $\geq 25 \mathrm{~kg} / \mathrm{m}^{2}$ and BMI $<25 \mathrm{~kg} / \mathrm{m}^{2}$, the median absolute weight loss was $5.00 \mathrm{~kg}(1.00$ $34.50 \mathrm{~kg})$ and $3.00 \mathrm{~kg}(2.00-4.50 \mathrm{~kg})$, respectively, and relative weight loss was $7.34 \%(1.00-36.00 \%)$ and $5.17 \%$ (3.00-7.00\%), respectively. Twelve patients $(27.27 \%)$ had no weight change, and 7 (15.91\%) patients had weight gain, with a median weight gain of $2.50 \mathrm{~kg}$ (1.50$10.00 \mathrm{~kg}$ ); these remaining 19 patients (12 patients with no weight change and 7 patients with weight gain) comprised the non-weight loss group.

\section{Reproductive Outcomes}

Of the 44 total patients, 30 underwent ART, and 14 patients attempted non-ART. A total of 29 (65.91\%) patients became pregnant; of these, 19/29 (65.52\%) underwent ART, and 10/ 29 (34.48\%) used non-ART methods. The pregnancy rate was non-significantly higher in the non-ART group than in the ART group $(71.43 \%$ and $63.33 \%$, respectively; $P=0.738$ ); the live birth rate was the same (both $50.00 \%$; $P=1.000$ ) between ART and non-ART. Of the 29 patients who successfully became pregnant, there were 35 clinical pregnancies; 22 patients delivered 26 healthy infants (24 singletons and 1 set of twins); 23 full-term and 2 pre-term live births; 17 girls and 9 boys; 3 patients had two pregnancies and live births. The live birth rate was $50.00 \%(22 / 44)$. Six patients had early intrauterine pregnancy loss, two had biochemical pregnancy loss, one had an ectopic pregnancy, 


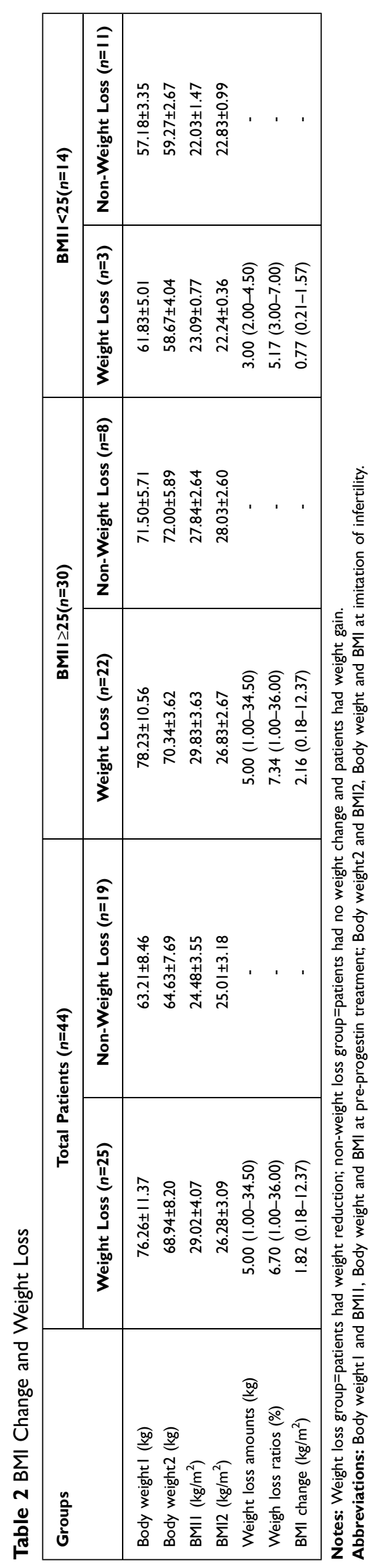

one experienced a stillbirth at 32 weeks, and two are still pregnant until as of the last follow-up (Figure 2).

Twenty-two pregnancies were delivered by cesarean section, and three pregnancies were delivered via vaginal delivery. The incidence of cesarean delivery was $88 \%(22 / 25)$.

\section{Correlation Between BMI/Weight Loss and Reproductive Outcomes}

Table 3 shows that pre-progestin treatment and pre-fertility treatment BMI were not associated with pregnancy or live birth rates. However, BMI $\geq 25 \mathrm{~kg} / \mathrm{m}^{2}$ was associated with early pregnancy loss $(50.00 \%$ vs $11.76 \%, P=0.038)$. The pregnancy and livebirth rates were significantly higher in the weight loss group than in the non-weight loss group $(88.00 \%$ vs $36.84 \%, P=0.001 ; 64.00 \%$ vs $31.58 \%$, $P=0.033$, respectively) and in patients with BMI $\geq 25 \mathrm{~kg} /$ $\mathrm{m}^{2}(86.37 \%$ vs $12.50 \%, P<0.001 ; 59.09 \%$ vs $0.00 \%$, $P=0.004$, respectively). In patients with BMI $<25 \mathrm{~kg} / \mathrm{m}^{2}$, weight loss had no effects on pregnancy and livebirth outcomes $(P>0.05)$. Furthermore, weight loss was not associated with early pregnancy loss $(P>0.05)$.

Of the 44 total patients, the pregnancy rate of patients with non-weight loss, weight loss $<5 \%$, and weight loss $\geq 5 \%$ was $36.84 \%, 80.00 \%$, and $90 \%$, respectively $(P=0.001)$; these values were $12.50 \%, 75.00 \%$, and $88.89 \%$, respectively, in patients with BMI $\geq 25 \mathrm{~kg} / \mathrm{m}^{2}$ $(P<0.001)$. Meanwhile, the live birth rate of patients with non-weight loss, weight loss $<5 \%$, and weight loss $\geq 5 \%$ was $0.00 \%, 50.00 \%$, and $61.11 \%$, respectively, in patients with BMI $\geq 25 \mathrm{~kg} / \mathrm{m}^{2}(P=0.010)$.

Of the 44 total patients, pregnancy loss was not different between weight loss group and non-weight loss group $(P=0.635)$.

\section{Factors Associated with Pregnancy in Regression Analysis}

Factors associated with pregnancy after conservative treatment in univariate analysis are shown in Table 4. Weight loss $\geq 5 \%$ was an independent positive factor for pregnancy adjusted for age at diagnosis, progestin treatment time, and endometrial thickness, with a relative risk of 10.448 (95\% confidence interval: 1.102, 99.056; $P=0.041$ ) (Table 5).

\section{Discussion}

Fertility preservation techniques have improved over the last two decades, but the barriers to engaging in improved reproductive outcomes are significant. Interventions 


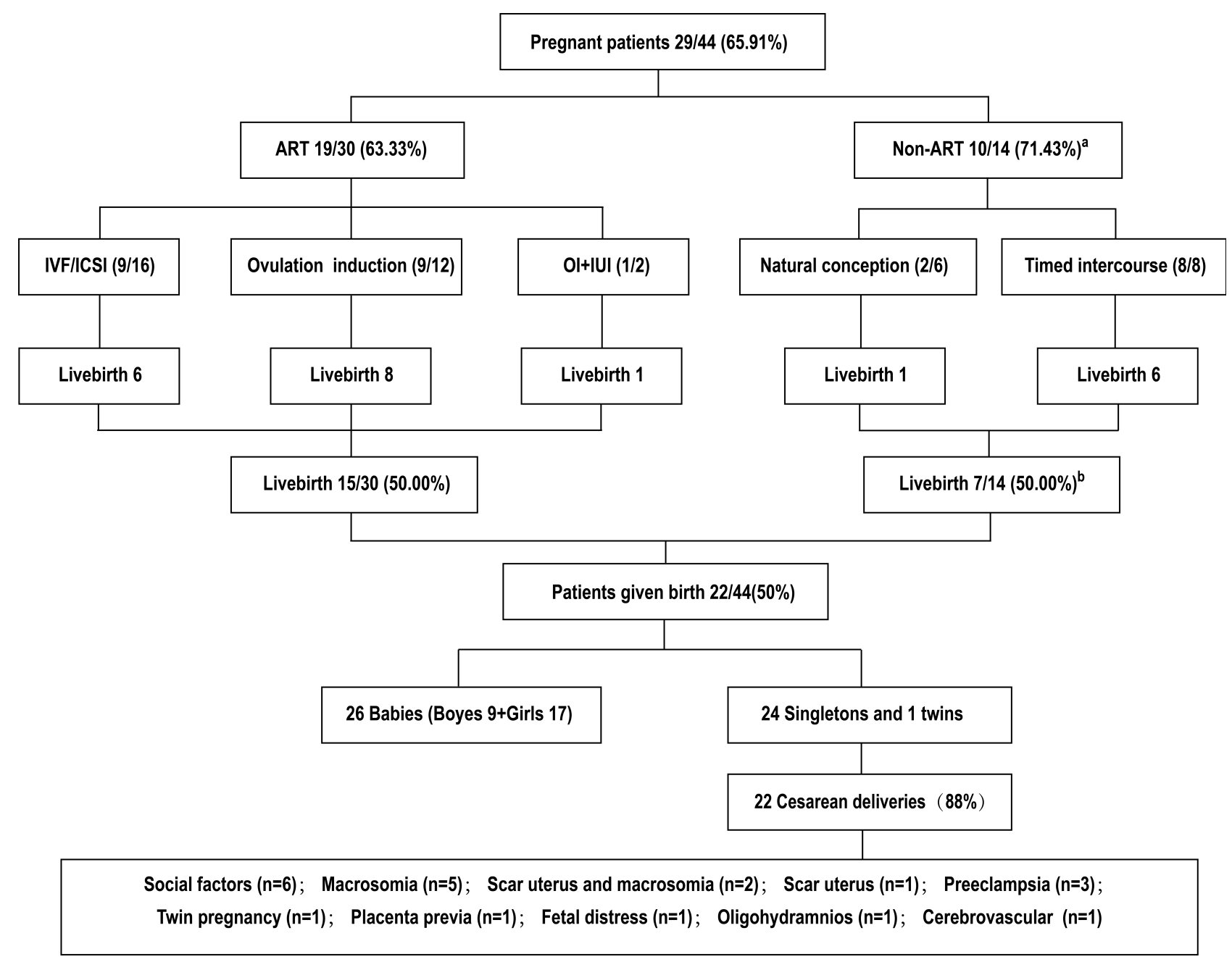

Figure 2 Infertility treatment after conservative treatment and reproductive outcomes.

Notes: $(\mathbf{A})$ the pregnancy rate of Non-ART patients was not different from the ART patients $(P=0.738)$; $(\mathbf{B})$ the livebirth rate of Non-ART patients was same as the ART patients $(P=1.000)$.

Abbreviations: ART, assisted reproductive therapy; IVF, In vitro fertilization; ICSI, Intracytoplasmic Sperm Injection; OI, ovulation induction; IUI, Intrauterine insemination.

targeting the etiology will contribute to achieve a satisfactory outcome. As the major risk factor for uterine neoplasms, obesity epidemic has become a global public health problem. ${ }^{16}$ We report herein for the first time that weight loss interventions improve reproductive outcomes in women with early-stage $\mathrm{EC}$ and $\mathrm{AH}$ who underwent fertility-sparing treatment. Weight loss of $\geq 5 \%$ was an independent positive factor for pregnancy after adjustment for age at diagnosis, progestin treatment duration, and endometrial thickness. Moreover, there was a favorable pregnancy rate $(65.91 \%)$ and live birth rate $(50.00 \%)$ after weight loss; these values are meaningfully higher than those reported in the literature. ${ }^{8,17}$ The study indicated that weight loss may provide a promising treatment option to preserve reproductive potential in conservative therapy. Therefore, it is of paramount importance that overweight and obese women are provided the necessary advice and support to achieve weight loss before pregnancy during and after fertility-sparing treatment.

The correlation between weight loss and reproductive outcomes in young women with $\mathrm{EC}$ and $\mathrm{AH}$ is rarely reported. To date, only a study by Park et al published in 2017 in Korea argued that weight change was not associated with pregnancy and live birth rates in young women with EC who undertook fertility preservation treatment; ${ }^{15}$ however, our current results differ from these prior results. The difference may derive from the existence of interventions for weight loss. Of note, progestin therapy is a widely accepted, effective treatment for $\mathrm{EC}$ and $\mathrm{AH}$; nonetheless, weight gain is a well-known paradoxical side effect. ${ }^{18}$ In the study by Park et al, ${ }^{15}$ weight loss interventions were not included, and a lower 
Table 3 BMIS/Weight Loss and Reproductive Outcomes

\begin{tabular}{|c|c|c|c|c|c|c|c|c|c|c|}
\hline & & \multicolumn{3}{|c|}{ Pregnancy n (\%) } & \multicolumn{3}{|c|}{ Pregnancy Loss $n(\%)^{a}$} & \multicolumn{3}{|c|}{ Live Birth n (\%) } \\
\hline & & Yes (29) & No (15) & $P$ value & Yes (8) & No (2I) & $P$ value & Yes (22) & No (22) & $P$ value \\
\hline \multicolumn{11}{|l|}{ BMIs } \\
\hline \multirow[t]{2}{*}{$\begin{array}{l}\text { Total } \\
(n=44)\end{array}$} & $\begin{array}{r}\text { BMII } \geq 25 \\
(n=30) \\
<25(n=\mid 4)\end{array}$ & $\begin{array}{l}20(66.67) \\
9(64.29)\end{array}$ & $\begin{array}{l}10(33.33) \\
5(35.71)\end{array}$ & 1.000 & $\begin{array}{c}8(40.00) \\
0\end{array}$ & $\begin{array}{l}12(60.00) \\
9(100.0)\end{array}$ & 0.033 & $\begin{array}{l}\text { I } 3(43.33) \\
9(64.29)\end{array}$ & $\begin{array}{l}\text { I7 (56.67) } \\
5(35.7 \mathrm{I})\end{array}$ & 0.332 \\
\hline & $\begin{array}{r}\text { BMI } 2 \geq 25 \\
(n=22) \\
<25(n=22)\end{array}$ & $\begin{array}{l}12(54.55) \\
17(77.27)\end{array}$ & $\begin{array}{l}10(45.45) \\
5(22.73)\end{array}$ & 0.110 & $\begin{array}{l}6(50.00) \\
2(11.76)\end{array}$ & $\begin{array}{l}6(50.00) \\
\text { I5 (88.24) }\end{array}$ & 0.038 & $\begin{array}{l}8(36.36) \\
14(63.64)\end{array}$ & $\begin{array}{l}14(63.64) \\
8(36.36)\end{array}$ & 0.131 \\
\hline \multicolumn{11}{|c|}{ Weight loss (WT) } \\
\hline $\begin{array}{l}\text { Total } \\
(n=44)\end{array}$ & $\begin{array}{r}\text { WT yes } \\
(n=25) \\
\text { No }(n=19)\end{array}$ & $\begin{array}{l}22(88.00) \\
7(36.84)\end{array}$ & $\begin{array}{l}3(12.00) \\
12(63.16)\end{array}$ & 0.001 & $\begin{array}{l}7(31.82) \\
\text { I (14.29) }\end{array}$ & $\begin{array}{l}15(68.18) \\
6(85.71)\end{array}$ & 0.635 & $\begin{array}{l}16(64.00) \\
6(31.58)\end{array}$ & $\begin{array}{l}9(36.00) \\
13(68.42)\end{array}$ & 0.033 \\
\hline $\begin{array}{l}\text { BMII } \geq 25 \\
(n=30)\end{array}$ & $\begin{array}{r}\text { WT yes } \\
(n=22) \\
\text { No }(n=8)\end{array}$ & $\begin{array}{l}19(86.37) \\
\text { I (12.50) }\end{array}$ & $\begin{array}{l}3(13.63) \\
7(87.50)\end{array}$ & $<0.001$ & $\begin{array}{l}7(36.84) \\
\text { I (100.0) }\end{array}$ & $\begin{array}{c}12(63.16) \\
0\end{array}$ & 0.400 & $\begin{array}{c}\text { I3 (59.09) } \\
0\end{array}$ & $\begin{array}{l}9(42.91) \\
8(100.0)\end{array}$ & 0.004 \\
\hline $\begin{array}{l}\text { BMII }<25 \\
(n=\mid 4)\end{array}$ & $\begin{array}{r}\text { WT yes } \\
(n=3) \\
\text { No }(n=I I)\end{array}$ & $\begin{array}{l}3(100.0) \\
6(54.55)\end{array}$ & $\begin{array}{c}0 \\
5(45.45)\end{array}$ & 0.258 & 0 & $\begin{array}{l}3(100.0) \\
6(100.0)\end{array}$ & - & $\begin{array}{l}3(100.0) \\
6(54.55)\end{array}$ & $\begin{array}{c}0 \\
5(45.45)\end{array}$ & 0.258 \\
\hline
\end{tabular}

Notes: ${ }^{a}$ pregnancy loss including 6 early intrauterine pregnancy losses and 2 biochemical pregnancy losses.

Abbreviations: BMII, BMI at pre-progestin treatment; BMI2, BMI initiation of fertility treatment.

Table 4 Associated Factors of Pregnancy Among Patients After Conservative Treatment in Univariate Analysis

\begin{tabular}{|c|c|c|c|}
\hline Category & Pregnancy & Non-Pregnancy & $\boldsymbol{P}$ \\
\hline Age at diagnosis, mean $\pm S D$ (years) & $30.72(4.18)$ & $33.40(2.56)$ & 0.033 \\
\hline Duration of progestin, mean $\pm S D$ (months) & $5.93(1.19)$ & $8.07(2.7 I)$ & $<0.001$ \\
\hline Weight change value, mean $\pm S D(\mathrm{~kg})$ & $-4.83(8.26)$ & $-1.37(4.28)$ & 0.024 \\
\hline FBG, mean $\pm S D(\mathrm{mmol} / \mathrm{L})$ & $5.46(0.85)$ & $5.49(1.05)$ & 0.069 \\
\hline Number of D\&C, mean $\pm S D$ (times) & $4.48(1.27)$ & $7.13(3.04)$ & 0.014 \\
\hline Endometrial thickness, mean $\pm S D(\mathrm{~mm})$ & $9.39(1.34)$ & $7.46(1.8)$ & $<0.001$ \\
\hline Weight loss group, $n$ (\%): & & & 0.001 \\
\hline Non-weight loss & $7(36.84)$ & $12(63.26)$ & \\
\hline Weight loss $<5 \%$ & $4(80.00)$ & I (20.00) & \\
\hline Weight loss $\geq 5 \%$ & $18(90.00)$ & $2(10.00)$ & \\
\hline
\end{tabular}

Notes: Mann-Whitney U-test

Abbreviation: number of D\&C: number of dilation and curettage.

Table 5 Risk Ratios (RR) for Pregnancy Using Logistic Regression Analysis

\begin{tabular}{|l|l|l|l|l|l|l|l|}
\hline \multirow{2}{*}{ Category } & \multirow{2}{*}{ Reference } & \multicolumn{3}{|c|}{ Univariate Analysis } & \multicolumn{3}{c|}{ Multivariate Analysis } \\
\cline { 3 - 8 } & & $\mathbf{R R}$ & $\mathbf{9 5 \%} \mathbf{C l}$ & P value & RR & $\mathbf{9 5 \%}$ CI & P value \\
\hline Weight loss ratios & Non-weight loss & & & & & & \\
\hline Weight loss $<5 \%$ & & 6.857 & $(0.634,74.189)$ & 0.113 & 16.673 & $(0.377,737.93)$ & 0.146 \\
\hline Weight loss $\geq 5 \%$ & & 15.429 & $(2.727,87.283)$ & 0.002 & 10.448 & $(1.102,99.056)$ & 0.041 \\
\hline
\end{tabular}

Notes: Multivariate analysis adjusted as age at diagnosis, duration of progestin, and endometrial thickness. 
proportion of patients with weight loss $(33.1 \%)$ and higher proportion of patients with weight gain (48.1\%) were reported; in addition, the post-treatment BMI was higher than the pre-treatment BMI $(25.99 \pm 5.94$ vs 25.51 $\pm 5.99 \mathrm{~kg} / \mathrm{m}^{2}$, respectively, $\left.P=0.034\right)$. In contrast, with weight loss interventions in the present study, a higher proportion of patients with weight loss was achieved $(56.82 \%)$, and weight gain was not evident (15.91\%) and displayed only a minor influence on reproductive outcomes (Additional Table 1). In patients who were overweight/obese in the current study, health education was provided, and the majority expressed interest in weight loss interventions in person; with a relatively long time to lose weight before pregnancy, 22 patients (73.3\%) lost weight, $18(81.8 \%)$ of whom weight loss $\geq 5 \%$. This emphasizes that non-pharmacological, health education-focused interventions may play an important role in achieving weight loss, which may improve outcomes from ovulatory cycles and pregnancy rates. ${ }^{19}$ In the study by Ashley et al regarding the relationship between obesity and endometrial cancer, they posit that there is "a lack of knowledge but opportunity for intervention". ${ }^{20}$

Furthermore, administration of metformin may account for some weight loss, as $72.73 \%$ of women in the present study used metformin because of insulin resistance. Metformin has been examined in multiple disease processes as a weight gain prevention tool, and it appears to impact appetite regulation both directly and indirectly due to its gastrointestinal side effects and a modified microbiome that helps to decrease caloric intake rather than increase energy expenditure. ${ }^{21}$

Moreover, different study population characteristics may lead to different conclusions. For instance, in the study by Park et al, at baseline, $46.10 \%$ patients had a BMI $\geq 25 \mathrm{~kg} / \mathrm{m}^{2}$, and $53.90 \%$ patients had a BMI $<25 \mathrm{~kg} / \mathrm{m}^{2}$; in contrast, in the present study, these percentages were $68.18 \%$ and $31.82 \%$, respectively. In a subgroup analysis, we found that weight loss meaningfully increased the pregnancy and live birth rates mainly in overweight/obese patients, but not in those with normal weight. Similar BMI-specific analyses were not included in the study of Park et al. ${ }^{15}$

A weight loss of $5 \%$, which is less than was required to achieve a normal BMI, may be meaningful to improve reproductive outcomes. In obese women with PCOS, only $2-5 \%$ of total body weight loss from baseline is generally accepted as clinically meaningful to improve ovulatory function and is more likely to result in spontaneous pregnancy; there is also evidence to support improved outcomes from ovulatory cycles and pregnancy at $5-10 \%$ of total body weight loss. ${ }^{22}$ In young women who received fertility-sparing treatment with $\mathrm{EC}$ and $\mathrm{AH}$ in the current study, we found that weight loss $\geq 5 \%$ was an independent positive factor for pregnancy after adjustment for age at diagnosis, progestin treatment duration, and endometrial thickness. The improvement on fertility resulting from weight loss but not BMI suggests that BMI is not associated with pregnancy and live birth rate; this finding is consistent that of Park et al. ${ }^{15}$

Weight loss is crucial and safe for the clinical management in young women undergoing fertility-sparing therapy, but further research concerning the correlation between weight loss and pregnancy loss is still needed. Some studies in a cancer-free population found that overweight and obesity before pregnancy increased pregnancy loss and decreased the live birth rate $;^{23-25}$ the present results confirm this. In this sense, weight loss in young women with $\mathrm{EC}$ and $\mathrm{AH}$ was meaningful to achieve positive pregnancy outcomes. However, weight loss did not seem to be associated with decreased pregnancy loss; this may be due to the small number of cases. However, this raises a further consideration: the amount of weight loss necessary to achieve benefits may differ according to the specific medical goal. Therefore, clinicians in medical weight management should consider that the target should be reproductive health improvement, rather than a specific, large number on the weight scale; moreover, individual patients respond differently to weight loss. Weight loss was at least unrelated to an increased risk of pregnancy loss; thus, it is safe to lose weight within appropriate limits.

Following weight loss intervention, there were more cases of spontaneous pregnancies or pregnancies by ovulation induction occurring soon after conservative treatment; however, this did not hold true for IVF-based pregnancies. Most women in the present study experienced infertility or subfertility with underlying disorders related to overweight/obesity and PCOS, conditions for which they should be encouraged to seek ART to aid with conception. A prior study reported that ART might increase the likelihood of pregnancy than spontaneous way $(39.4 \%$ vs $14.9 \%$ ) and decreases the interval to conception. ${ }^{8,26,27}$ In contrast, in the present study, the non-ART group achieved a numerically more favorable for pregnancy rate $(71.43 \%$ vs $63.33 \%)$ compared to ART and the same 
live birth rate $(50.00 \%$ for both groups). Weight loss improved spontaneous pregnancies.

Furthermore, only 16 out of 44 patients required the aid of IVF, and only 9 of the 16 patients who received IVF in the study successfully conceived. To date, limited studies, mainly case reports and retrospective studies, have investigated the association between controlled ovarian hyperstimulation and cancer risk, which mainly refers to endometrial and ovarian cancer risk; the conclusions of these studies were inconsistent across trials; thus, the present understanding is inconclusive given the short followup times and lack of information on important confounders. ${ }^{28-30}$ Outcomes in the present study indicated a benefit of weight reduction for not only improving pregnancy rates, but also reducing the need for IVF.

The study demonstrated a significantly high incidence of cesarean delivery (22 of 25 [88\%] pregnancies) after conservative treatment. To some extent, the increased cesarean rate in these women appears to be associated with hypertensive disorders and macrosomia related to gestational diabetes mellitus, both of which may be associated with a higher pre-treatment and peri-gravid BMI. Furthermore, proper pre-pregnancy weight loss and peri-gravid weight gain are crucial to improve obstetric outcomes. Meanwhile, owing to socially derived misconceptions concerning the mode of delivery among neoplastic disease survivors, there was an increased incidence of cesarean delivery. Accordingly, caring for these young cancer patients requires collaboration between a dedicated, adherent patient and the medical team comprising a gynecological oncologist, reproductive endocrinologist, and obstetric experts.

This study's primary limitation is that it was a retrospective analysis conducted at a single center with a small number of cases. Hence, further large-scale, welldesigned randomized controlled trials are necessary to clarify the findings. The lack of immunohistochemical markers analyses is also a limitation in this study, which may be helpful in predicting the response to conservative treatment on pretreatment and follow-up specimens. ${ }^{31}$

\section{Conclusion}

The results of the present retrospective study suggest that there is a significant association between the weight loss and favorable reproductive outcomes of $\mathrm{EC}$ and $\mathrm{AH}$ patients who received fertility-sparing treatment, especially, overweight or obese ones will benefit from the weight loss interventions. weight loss $\geq 5 \%$ significantly increased pregnancy and live birth rate in patients with $\mathrm{BMI} \geq 25 \mathrm{~kg} / \mathrm{m}^{2}$. Obesity is associated with increased EC incidence, infertility and healthcost. As a modifiable risk factor, obesity can be managed with a multidisciplinary approach. Further exploration on different kinds of weight loss interventions and relative weight loss in fertility-sparing treatment is needed to develop informed, targeted interventions for patients as well as long-term follow-up data for clinicians, to improve the quality of life in survivors of gynecologic cancers, especially, reduce the burden of health care costs.

\section{Data Sharing Statement}

All data generated or analyzed during this study are included in this published article (and its supplementary information files).

\section{Ethics Approval and Consent to Participate}

This study was conducted in accordance with the Declaration of Helsinki.

\section{Acknowledgments}

The authors thank to the assistance of Dr. Jie Liu in data statistics (Department of Neurology, Tianjin Medical University General Hospital, Tianjin, China; Laboratory of Epidemiology, Tianjin Neurological Institute \& Department of Neurology).

\section{Funding}

This work was supported by grants from the National Natural Science Foundation of China (No.81802617); Tianjin Science and Technology Plan Project (18ZXDBSY00220) and Tianjin Municipal Natural Science Foundation (No.18JCQNJC81200).

\section{Disclosure}

All authors declare that they have no conflicts of interest.

\section{References}

1. Koh WJ, Abu-Rustum NR, Bean S, et al. Uterine Neoplasms, Version 1.2018, NCCN Clinical Practice Guidelines in Oncology. J Natl Compr Canc Netw. 2018;16(2):170-199. doi:10.6004/jncen.2018.0006

2. Lortet-Tieulent J, Ferlay J, Bray F, Jemal A. International patterns and trends in endometrial cancer incidence, 1978-2013. J Natl Cancer Inst. 2018;110(4):354-361. doi:10.1093/jnci/djx214

3. Shaw E, Farris M, McNeil J, Friedenreich C. Obesity and endometrial cancer. Recent Results Cancer Res. 2016;208:107-136.

4. Terzic M, Norton M, Terzic S, Bapayeva G, Aimagambetova G. Fertility preservation in endometrial cancer patients: options, challenges and perspectives. Ecancermedicalscience. 2020;14:1030. doi:10.3332/ecancer.2020.1030 
5. Casadio P, La Rosa M, Alletto A, et al. Fertility sparing treatment of endometrial cancer with and without initial infiltration of myometrium: a single center experience. Cancers. 2020;12(12):3571. doi:10.3390/ cancers 12123571

6. Soliman PT, Oh JC, Schmeler KM, et al. Risk factors for young premenopausal women with endometrial cancer. Obstet Gynecol. 2005;105(3):575-580. doi:10.1097/01.AOG.0000154151.14516. $\mathrm{f} 7$

7. Gallos ID, Yap J, Rajkhowa M, Luesley DM, Coomarasamy A, Gupta JK. Regression, relapse, and live birth rates with fertility-sparing therapy for endometrial cancer and atypical complex endometrial hyperplasia: a systematic review and metaanalysis. Am J Obstet Gynecol. 2012;207(4):266.e1-12. doi:10.1016/j.ajog.2012.08.011

8. Li M, Guo T, Cui R, Feng Y, Bai H, Zhang Z. Weight control is vital for patients with early-stage endometrial cancer or complex atypical hyperplasia who have received progestin therapy to spare fertility: a systematic review and meta-analysis. Cancer Manag Res. 2019;11:4005-4021. doi:10.2147/CMAR.S194607

9. Giampaolino P, Di Spiezio Sardo A, Mollo A, et al. Hysteroscopic endometrial focal resection followed by levonorgestrel intrauterine device insertion as a fertility-sparing treatment of atypical endometrial hyperplasia and early endometrial cancer: a retrospective study. J Minim Invasive Gynecol. 2019;26(4):648-656. doi:10.1016/j. jmig.2018.07.001

10. Mazzon I, Corrado G, Masciullo V, Morricone D, Ferrandina G, Scambia G. Conservative surgical management of stage IA endometrial carcinoma for fertility preservation. Fertil Steril. 2010;93 (4):1286-1289. doi:10.1016/j.fertnstert.2008.12.009

11. Yang B, Xu Y, Zhu Q, et al. Treatment efficiency of comprehensive hysteroscopic evaluation and lesion resection combined with progestin therapy in young women with endometrial atypical hyperplasia and endometrial cancer. Gynecol Oncol. 2019;153(1):55-62. doi:10.1016/j.ygyno.2019.01.014

12. Best D, Avenell A, Bhattacharya S. How effective are weight-loss interventions for improving fertility in women and men who are overweight or obese? A systematic review and meta-analysis of the evidence. Hum Reprod Update. 2017;23(6):681-705. doi:10.1093/ humupd/dmx027

13. Wise MR, Jordan V, Lagas A, et al. Obesity and endometrial hyperplasia and cancer in premenopausal women: a systematic review. $\mathrm{Am}$ $J$ Obstet Gynecol. 2016;214(6):689.e1-689.e17. doi:10.1016/j. ajog.2016.01.175

14. Silvestris E, de Pergola G, Rosania R, Loverro G. Obesity as disruptor of the female fertility. Reproductive Biol Endocrinol. 2018;16 (1):22. doi:10.1186/s12958-018-0336-Z

15. Park JY, Seong SJ, Kim TJ, Kim JW, Bae DS, Nam JH. Significance of body weight change during fertility-sparing progestin therapy in young women with early endometrial cancer. Gynecol Oncol. 2017;146(1):39-43. doi:10.1016/j.ygyno.2017.05.002

16. Kiesel L, Eichbaum C, Baumeier A, Eichbaum M. Obesity epidemic - the underestimated risk of endometrial cancer. Cancers. 2020;12 (12):3860. doi:10.3390/cancers12123860

17. Wei J, Zhang W, Feng L, Gao W. Comparison of fertility-sparing treatments in patients with early endometrial cancer and atypical complex hyperplasia: a meta-analysis and systematic review. Medicine. 2017;96(37):e8034. doi:10.1097/MD.000000000000 8034
18. Cholakian D, Hacker K, Fader AN, Gehrig PA, Tanner EJ. Effect of oral versus intrauterine progestins on weight in women undergoing fertility preserving therapy for complex atypical hyperplasia or endometrial cancer. Gynecol Oncol. 2016;140(2):234-238. doi:10.1016/j. ygyno.2015.12.010

19. Fink A, Cieslak S, Rosenbach F. Non-Pharmacological interventions for the prevention of weight gain in schizophrenic patients treated with antipsychotic medication. Psychiatr Prax. 2015;42(7):359-369. doi: $10.1055 / \mathrm{s}-0035-1552670$

20. Haggerty AF, Sarwer DB, Schmitz KH, Ko EM, Allison KC, Chu CS. Obesity and endometrial cancer: a lack of knowledge but opportunity for intervention. Nutr Cancer. 2017;69(7):990-995. doi:10.1080/01635581.2017.1359313

21. Yerevanian A, Soukas AA. Metformin: mechanisms in human obesity and weight loss. Curr Obes Rep. 2019;8(2):156-164. doi:10.1007/s13679-019-00335-3

22. Crosignani PG, Colombo M, Vegetti W, Somigliana E, Gessati A, Ragni G. Overweight and obese anovulatory patients with polycystic ovaries: parallel improvements in anthropometric indices, ovarian physiology and fertility rate induced by diet. Human Reproduction. 2003;18(9):1928-1932. doi:10.1093/humrep/deg367

23. Cavalcante MB, Sarno M, Peixoto AB, Araujo Júnior E, Barini R. Obesity and recurrent miscarriage: a systematic review and meta-analysis. J Obstet Gynaecol Res. 2019;45(1):30-38. doi:10.1111/jog.13799

24. Kawwass JF, Kulkarni AD, Hipp HS, Crawford S, Kissin DM, Jamieson DJ. Extremities of body mass index and their association with pregnancy outcomes in women undergoing in vitro fertilization in the United States. Fertil Steril. 2016;106(7):1742-1750. doi:10.1016/j.fertnstert.2016.08.028

25. Boots C, Stephenson MD. Does obesity increase the risk of miscarriage in spontaneous conception: a systematic review. Semin Reprod Med. 2011;29(6):507-513. doi:10.1055/s-0031-1293204

26. Lowe MP, Cooper BC, Sood AK, Davis WA, Syrop CH, Sorosky JI. Implementation of assisted reproductive technologies following conservative management of FIGO grade I endometrial adenocarcinoma and/or complex hyperplasia with atypia. Gynecol Oncol. 2003;91 (3):569-572. doi:10.1016/j.ygyno.2003.08.007

27. Zhou R, Yang Y, Lu Q, et al. Prognostic factors of oncological and reproductive outcomes in fertility-sparing treatment of complex atypical hyperplasia and low-grade endometrial cancer using oral progestin in Chinese patients. Gynecol Oncol. 2015;139(3):424-428. doi:10.1016/j.ygyno.2015.09.078

28. Bozdag G, Yarali H, Polat M, Esinler I, Tiras B, Ayhan A. ICSI outcome following conservative fertility sparing management of endometrial cancer. Reprod Biomed Online. 2009;18(3):416-420. doi:10.1016/S1472-6483(10)60102-2

29. Kim MJ, Choe SA, Kim MK, Yun BS, Seong SJ, Kim YS. Outcomes of in vitro fertilization cycles following fertility-sparing treatment in stage IA endometrial cancer. Arch Gynecol Obstet. 2019;300 (4):975-980. doi:10.1007/s00404-019-05237-2

30. Zapardiel I, Cruz M, Diestro MD, Requena A, Garcia-Velasco JA. Assisted reproductive techniques after fertility-sparing treatments in gynaecological cancers. Hum Reprod Update. 2016;22(3):281-305. doi:10.1093/humupd/dmv066

31. Travaglino A, Raffone A, Saccone G, et al. Immunohistochemical predictive markers of response to conservative treatment of endometrial hyperplasia and early endometrial cancer: a systematic review. Acta Obstet Gynecol Scand. 2019;98(9):1086-1099. doi:10.1111/aogs.13587-\# 


\section{Publish your work in this journal}

Cancer Management and Research is an international, peer-reviewed open access journal focusing on cancer research and the optimal use of preventative and integrated treatment interventions to achieve improved outcomes, enhanced survival and quality of life for the cancer patient.
The manuscript management system is completely online and includes a very quick and fair peer-review system, which is all easy to use. Visit http://www.dovepress.com/testimonials.php to read real quotes from published authors. 